\title{
PERANCANGAN SISTEM INFORMASI PENJUALAN KOSMETIK UNTUK WILAYAH PASAR MINGGU
}

\author{
Kamal Al Fatah ${ }^{1}$, Lusi Ariyani², Noni Selvia ${ }^{3}$ \\ ${ }^{1,2,3}$ Teknik Informatika, Fakultas Teknik dan Ilmu Komputer, Universitas Indraprasta PGRI \\ Jalan Raya Tengah No 80, Kelurahan Gedong, Pasar Rebo, Jakarta Timur \\ 1kamalalfatah23@gmail.com, ${ }^{2}$ lusiariyani0312@gmail.com, ${ }^{3}$ noni.selvia@gmail.com
}

\begin{abstract}
ABSTRAK
Adapun identifikasi masalah berdasarkan latar belakang yang telah penulis uraikan sebagai berikut, Penyimpanan data stok barang masih menggunakan media kertas yang membutuhkan waktu kurang lebih satu hari untuk melakukan penginputan data stok barang, Proses transaksi penjualan masih manual menggunakan nota bon sehingga memperlambat proses transaksi penjualan terhadap pelanggan serta adanya kesalahan yang terjadi pada saat memperhitungkan harga barang,Pembuatan laporan dilakukan secara manual menggunakan buku besar dan media kertas dan belum terkomputerisasi dengan baik memerlukan waktu setidaknya satu hari. Tujuan dari penelitian yang penulis lakukan ini bertujuan untuk memberikan kemudahan pengelolaan data Toko Kosmetik Wati. Pemrosesan data dipercepat keamanan dan akurasi data terjamin dan sumber daya manusia menjadi lebih efisien Metodologi penelitian yang dilakukan dalam sistem pengolahan data ini adalah metode pengumpulan seperti wawancara dan studi pustaka yang berkaitan dengan permasalahan sistem informasi Karyawan data pelanggan data produk data pemasok dan transaksi dapat dengan mudah mengumpulkan dan menyimpan data dengan tingkat efisiensi dan konsistensi data yang lebih terjamin. Hasil akhir penelitian Mengurangi masalah terdapatnya dalam perhitungan jumlah dan harga barang serta mengurangi kesalahan pada laporan keuangan sehingga dapat meningkatkan akurasi data.
\end{abstract}

Kata Kunci : Toko Kosmetik Wati, Java, Netbeans

\begin{abstract}
The identification of the problem based on the background that the author has described as follows, Storage of stock data still uses paper media which takes approximately one day to input stock data. The sales transaction process is still manual using a receipt so that it slows down the process of sales transactions to customers. as well as an error that occurred when calculating the price of goods. Reporting is done manually using ledgers and paper media and has not been computerized properly, it takes at least one day. The purpose of the research that the author did is to provide convenience in data management of Wati Cosmetics Store. Data processing is accelerated, data security and accuracy are guaranteed and human resources are more efficient. The research methodology carried out in this data processing system is collection methods such as interviews and literature studies related to information system problems. Employee data, customer data, product data, supplier data and transactions can be easily accessed. collect and store data with a more guaranteed level of efficiency and data consistency. The final results of the study Reduce problems in calculating the number and price of goods and reduce errors in financial reports so as to improve data accuracy.
\end{abstract}

Key Word: Wati Cosmetics Shop, Java, Netbeans

\section{PENDAHULUAN}

Toko Kosmetik Wati Untuk Wilayah Pasar Minggu adalah suatu usaha yang menyediakan kebutuhan mulai dari alat kecantikan, skincare, minyak wangi, dan aksesoris lainnya diperuntukan bagi masyarakat khususnya kaum wanita. Toko Kosmetik adalah salah satu badan usaha yang bergerak di bidang penjualan, dan beberapa penjualannya masih konvensional (Frieyadie \& Fatayat, 2019). Toko Kosmetik Wati Untuk Wilayah Pasar Minggu mulai beroperasi pada tanggal 21 April 2014 dan beralamat di Pasar Minggu jalan Swadaya 1, Jakarta Selatan. Toko Kosmetik Wati Untuk Wilayah Pasar Minggu.Agar Toko Kosmetik bisa bersaing dalam menjalankan bisnisnya, sebuah website bisa menjadi solusi yang dapat menyediakan informasi produk yang diinginkan oleh konsumen. (Putri, 2015) akan tetapi sistem yang berjalan untuk mengelola datanya masih dilakukan secara manual, kesulitan dalam mengelola data harga barang. Berdasarkan latar belakang permasalahan diatas, penulis 
berminat untuk membuat penelitian yang berkaitan dengan sistem penyediaan dan penjualan barang pada Toko Kosmetik Wati Untuk Wilayah Pasar Minggu, serta mencoba memberikan solusi yaitu dengan memberikan rancangan sistem penjualan barang pada Toko Kosmetik Wati Untuk Wilayah Pasar Minggu yang berjudul "Perancangan Sistem Informasi Penjualan Kosmetik Dengan Perencanaan Tata Letak Untuk Wilayah Pasar Minggu "

Adapun penelitian relevan yang sejalan dengan penelitian ini Penelitian oleh Hambalah (2021) Strategi pemasaran inovatif perusahaan kosmetik ditengah pandemi covid 19 di Indonesia, Penelitian oleh Cahyani \& Syarifah (2020), Peranan Religiusitas dalam menjelaskan intensi membeli kosmetik berlabel halal, Penelitian oleh SAFTIANA (2014), Analisis hubungan rasio konsentrasi, intensitas iklan, dan profitabilitas industry kosmetik di Indonesia, Penelitian oleh (Sa et al., 2019), Kosmetik kaolin dalam bidang farmasi.

\section{METODE PENELITIAN}

Desain penelitian yang saya ambil merupakan alat yang dapat digunakan untuk melaksanakan dan mencapai suatu penelitian yang digunakan secara teratur dan logis, Penelitian ini dilakukan secara kualitatif untuk mengetahui data terkait pengembangan bahan alam yang digunakan.(Tiara Putri et al., 2021) Tempat penelitian dilakukan di Toko Kosmetik Wati di Wilayah Pasar Minggu Kota Jakarta Selatan, Metode pengumpualan data yang saya gunakan dengan cara observasi, wawancara,studi literatur,dan survei. Teknik analisis penelitian dalam penelitian ini dengan metode kualitatif dengan pendekatan teknik deskriptif. Dalam pengembangan sistem pada Toko Kosmetik Wati Untuk Wilayah Pasar Minggu penulis melakukan langkah-langkah yaitu menganalisa kebutuhan sistem, studi kepustakaan, merancang sistem, pengujian sistem, implementasi sistem. Tujuan penelitian membuat sistem penjualan, pendataan barang, perhitungan barang, pembuatan struk pembelian, stok barang, dan pembuatan laporan dapat mempermudah dalam melakukan proses penjualan barang baik pada konsumen maupun pemilik toko. Manfaat penelitian Memberikan pemahaman kepada penulis mengenai konsep proses sistem penjualan pada Toko Kosmetik Wati untuk wilayah Pasar Minggu. Hasil akhir penelitian Mengurangi masalah terdapatnya dalam perhitungan jumlah dan harga barang serta mengurangi kesalahan pada laporan keuangan sehingga dapat meningkatkan akurasi data.

\section{HASIL DAN PEMBAHASAN}

Aplikasi sistem informasi Toko Kosmetik Wati yang terkomputerisasi sehingga dapat dihasilkan informasi yang lebih cepat, tepat dan akurat:

1. Membangun sistem informasi yang telah terkomputerisasi dan dapat membantu kinerja admin dalam pendataan Kosmetik , Transaksi, pembuatan laporan Masuk dan Keluar dan pembuatan daftar kosmetik yang sudah selesai.

2. Perancangan database sistem dalam menyimpan data agar lebih efisien dan lebih akurat, dapat mengurangi kehilangan data.

3. Pembuatan sistem informasi yang dapat dimengerti oleh semua pihak Toko Kosmetik Wati.

\section{Dekomposisi Fungsi Sistem yang Diusulkan}

Menurut (Soufitri, 2019) Data Flow Diagram (DFD) adalah representasi grafis dari aliran data melalui sistem informasi.

Dekomposisi fungsi dimaksudkan untuk mengetahui gambaran fungsi-fungsi proses dan bentuk masukan serta keluaran yang terdapat pada sistem yang akan dijalankan. Berikut ini gambaran dari dekomposisi fungsi sistem:

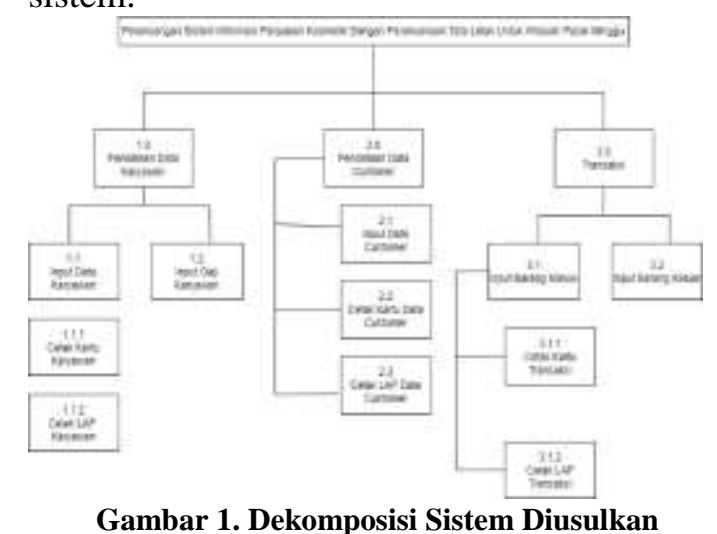




\section{Diagram Konteks yang Berjalan}

(Wijaya, 2016) Diagram konteks adalah diagram yang terdiri dari suatu proses yang menggambarkan ruang lingkup sistem.

Aliran data sistem yang berjalan berikutnya digambarkan pada diagram konteks berikut :

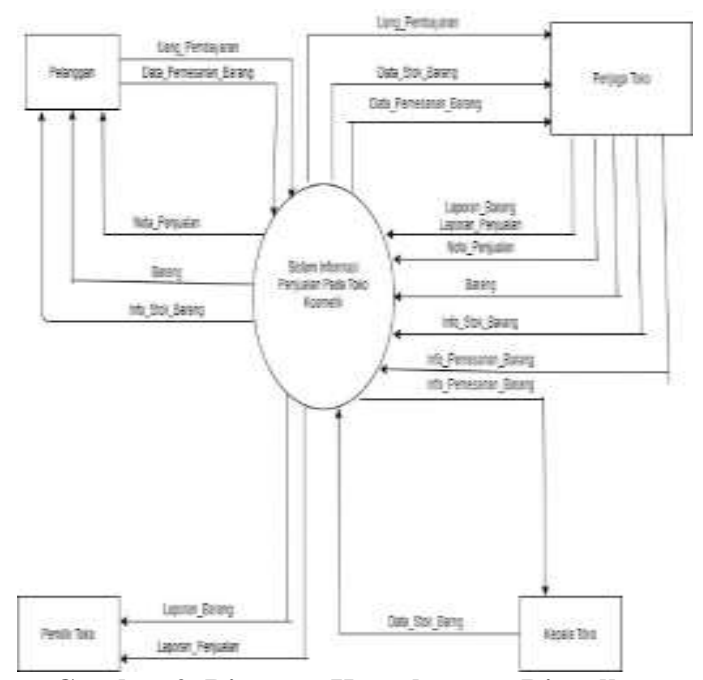

Gambar 2. Diagram Konteks yang Diusulkan

Entity Relationship Diagram (ERD) “Entity Relationship Diagram (ERD) adalah ERD adalah model yang menjelaskan hubungan antar data dalam database berdasarkan objek data yang mendasarinya yang memiliki hubungan antar relasi.”. (Ibeng, 2018)
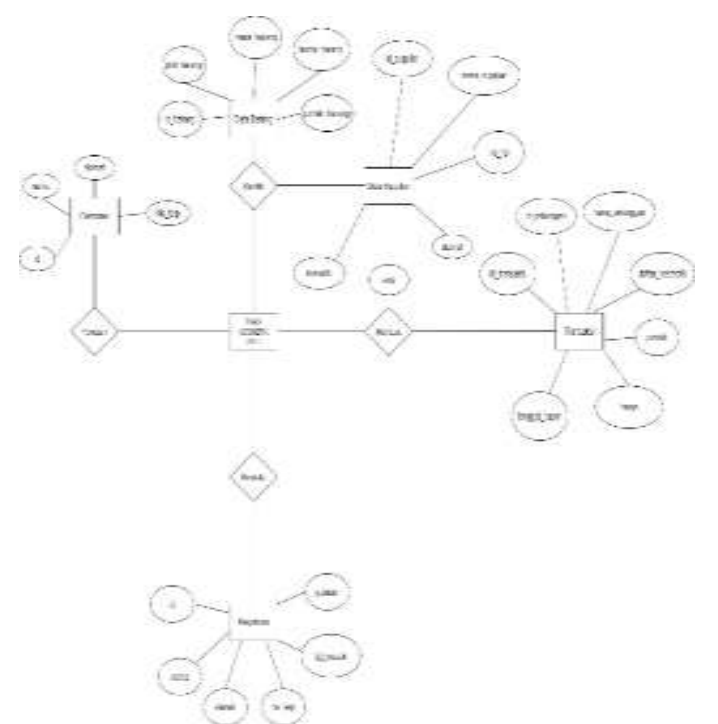

Gambar 3. Entity relationship Diagram (ERD)
Tampilan Layer Login

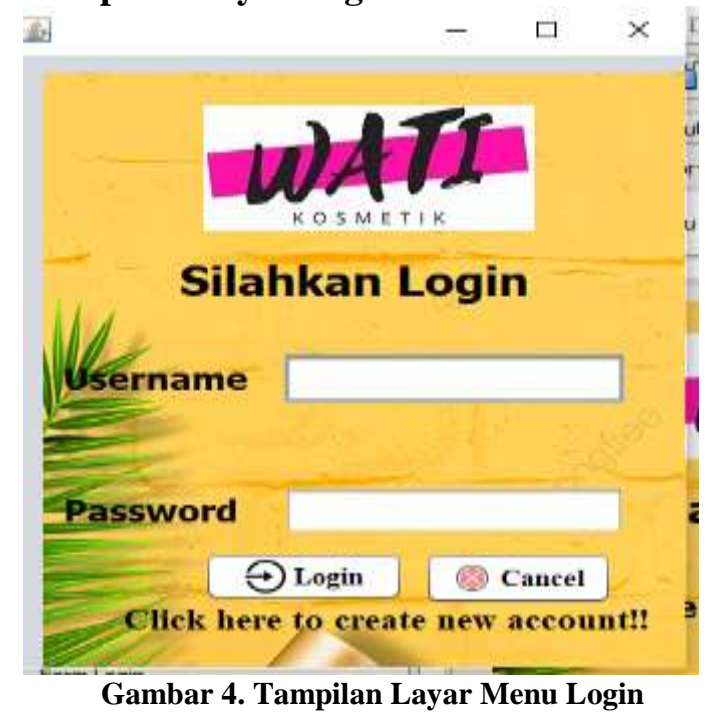

Menu login Admin digunakan sebagai kata keyword sebelum admin memasuki program utama. Menu ini bertujuan untuk mengamankan program supaya tidak dapat digunakan oleh orang lain kecuali admin.

\section{Tampilan Layer Menu Utama}

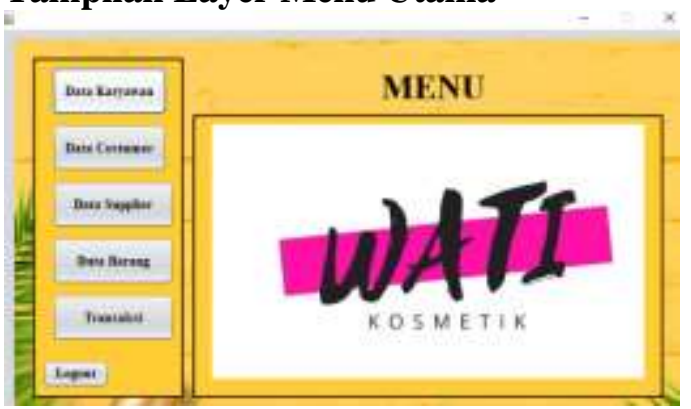

Gambar 5. Tampilan Layar Menu Utama

Menu diatas menampilkan tampilan menu utama sistem informasi pemesanan barang. Menu ini berfungsi untuk memasukkan datadata yang berkaitan dengan Data Barang, Data Karyawan, Data Customer, Data Supplier, dan Transaksi

\section{Tampilan Layer Data Customer}

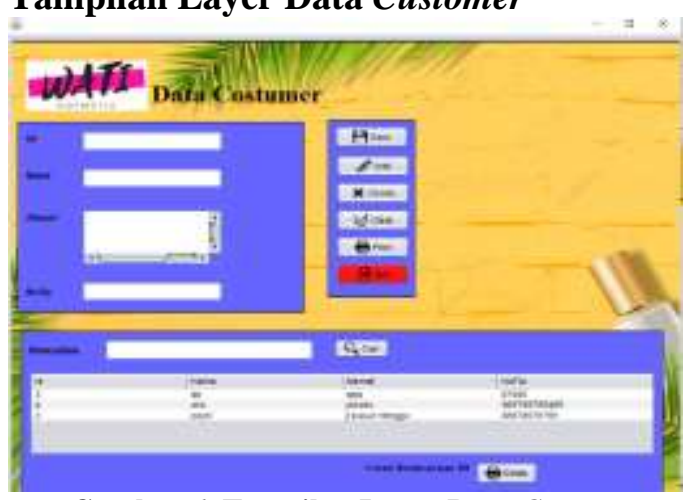

Gambar 6. Tampilan Layer Data Customer 
Pada Tampilan ini admin dapat meng-input Data Customer, Melakukan perubahan Data Customer serta dapat menghapus Data Customer.

\section{Tampilan Layer Data Karyawan}

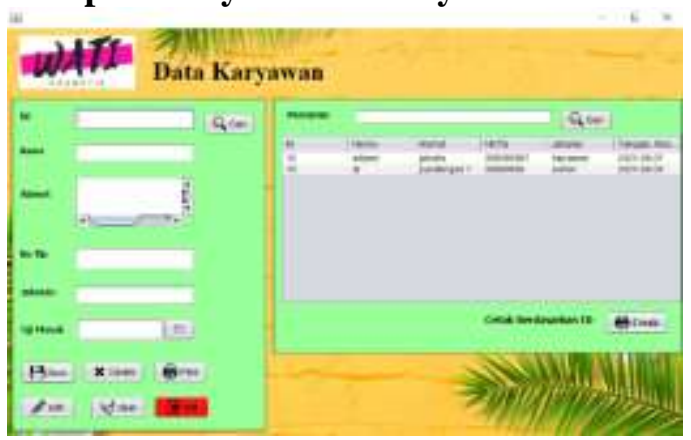

Gambar 7. Tampilan Layer Data Karyawan

Pada tampilan ini admin dapat meng-input Data Karyawan , siapa saja yang sudah mulai bekerja dan sudah resmi menjadi karyawan di Toko Wati Kosmetik.

\section{Tampilan Layer Data Barang}

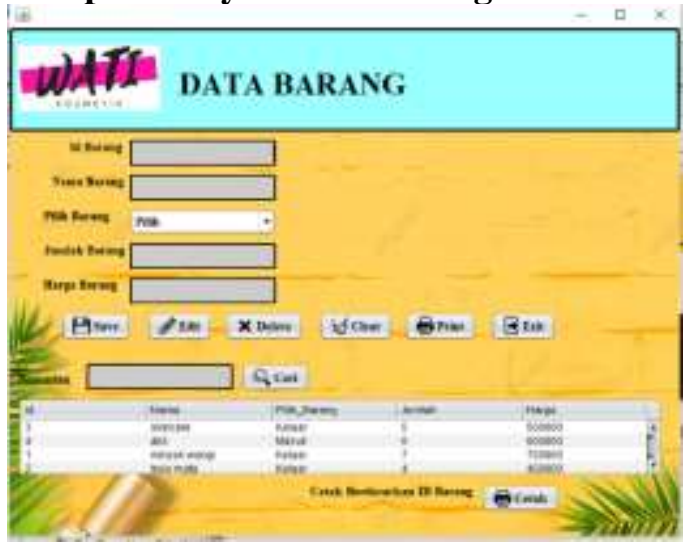

Gambar 8. Tampilan Layer Data Barang

Pada Tampilan ini admin dapat meng-input Data Barang, Melakukan perubahan Data Barang serta dapat menghapus Data Barang.

\section{Tampilan Layer Transaksi}

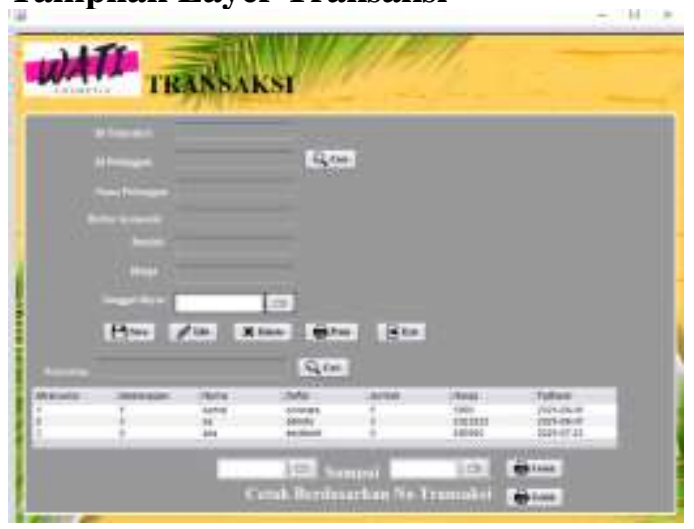

Gambar 9. Tampilan Layer Transaksi
Pada Tampilan ini admin dapat meng-input Transaksi, Melakukan perubahaan pada Transaksi serta dapat menghapus Transaksi.

\section{Tampilan Laporan Transaksi}

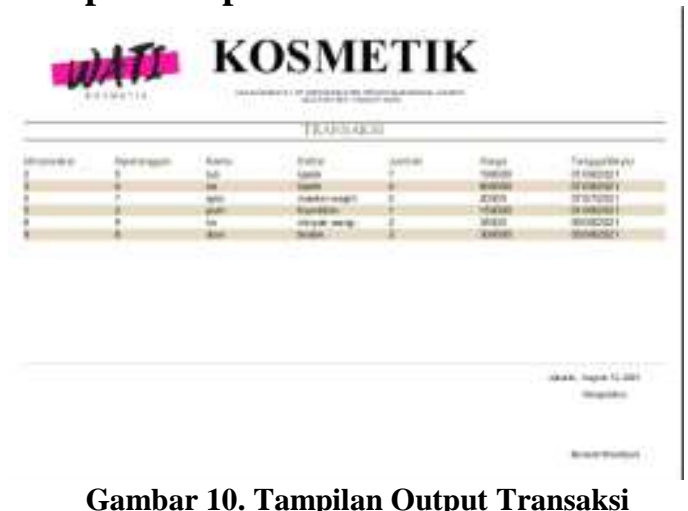

Pada Layer ini Admin dapat memberikan Laporan Transaksi Yang Membeli Kosmetik Pada Setiap Bulannya.

\section{SIMPULAN DAN SARAN}

Dari hasil analisis penelitian dan implementasi sistem aplikasi informasi penjualan Kosmetik Pada Toko Wati Untuk Wilayah Pasar Minggu, maka dapat diambil beberapa kesimpulan berikut: Dengan adanya aplikasi informasi penjualan, maka masalah pendataan data barang dapat menjadi lebih mudah, karena bentuk proses transaksi dihubungkan dengan database yang saling terintegrasi.

Dengan adanya sistem aplikasi informasi penjualan ini, maka pencarian data barang dan data penjualan lebih mudah dan lebih cepat karena data barang dan data penjualan sudah tersimpan di dalam aplikasi,Dengan adanya aplikasi informasi penjualan ini dapat menunjang proses penjualan pada Toko Kosmetik Wati Untuk Wilayah Pasar Minggu dan kemungkinan terjadi kesalahan saat transaksi menjadi lebih kecil, Dengan adanya aplikasi informasi penjualan ini, pembuatan laporan menjadi lebih mudah karena hanya perlu menggunakan salah satu menu yang ada pada aplikasi ini untuk mencetak laporan.

Saran pengembangan dari penelitian Sebelum aplikasi informasi penjualan diterapkan, sebaiknya dilakukan pengarahan dan pelatihan khusus untuk karyawan yang akan menggunakan aplikasi tersebut agar mereka dapat mengetahui dan memahami cara kerja 
aplikasi tersebut, Walaupun sudah berbasis komputer, ketelitian dalam meng-input data perlu diperhatikan untuk meminimalisir human error, Pemeliharaan dan pengembangan sistem harus terus dilakukan dan dievaluasi secara berkala agar dapat mencapai hasil yang maksimal sesuai dengan kebutuhan toko.

\section{DAFTAR PUSTAKA}

Cahyani, L. I., \& Syarifah, D. (2020). Peranan Religiusitas dalam Menjelaskan Intensi Membeli Kosmetik Berlabel Halal. INSAN Jurnal Psikologi Dan Kesehatan Mental, $\quad 5(2), \quad 142$. https://doi.org/10.20473/jpkm.v5i22020 .142-149

Frieyadie, \& Fatayat, U. (2019). Penggunaan Model Waterfall Dalam Perancangan Aplikasi Penjualan Kosmetik Berbasis Web. Jurnal Riset Informatika, 1(4), 159-166.

http://ejournal.kresnamediapublisher.co $\mathrm{m} /$ index.php/jri/article/view/84

Hambalah, F. (2021). Strategi Pemasaran Inovatif Perusahaan Kosmetik Di Tengah Pandemi Covid-19 Di Indonesia. Jurnal Analitika Bisnis, Ekonomi, Sosial Dan ..., 1, 189-198. http://jabeistik.upnjatim.ac.id/index.php /jabeistik/article/view/22

Ibeng. (2018). Pengertian Entity Relationship Diagram (ERD). In Www.Pendidikanku.Org: Vol. xii (Issue 33).

Putri, A. (2015). Perkembangan Penggunaan Produk Kosmetik Di Indonesia Amelia Putri Fakultas Bisnis dan Ekonomika Universitas Surabaya. Fakultas Bisnis Universitas Surabaya, 59-64.

Sa, H., Abdassah, M., \& Yohana Chaerunisaa, A. (2019). Aplikasi Kaolin dalam Farmasi dan Kosmetik Kaolin Application in Pharmaceuticals and Cosmetics. Pharmaceutical Journal of Indonesia, 16(02), 334-346.

Saftiana, Y. (2014). Analisis Hubungan Rasio Konsentrasi , Intensitas Iklan, Dan Profitabilitas Industri Kosmetik Di Indonesia. Jurnal Manajemen Dan Bisnis Sriwijaya, 12(4), 243-258. https://doi.org/10.29259/jmbs.v12i4.31 79

Soufitri, F. (2019). Perancangan Data Flow Diagram Untuk Sistem Informasi
Sekolah (Studi Kasus Pada Smp Plus Terpadu). Ready Star, 2(1), 240-246.

Tiara Putri, L., Syukri, Y., \& Werdyani, S. (2021). Aplikasi Gold Nanopartikel dengan Bahan Alam sebagai Kosmetik Pemutih Wajah: Tinjauan Sistematis. Jurnal Sains Farmasi \& Klinis, 8(2), 116.

https://doi.org/10.25077/jsfk.8.2.116127.2021

Wijaya, K. M. (2016). Pengertian CD (Context Diagram) dan DFD (Data Flow Diagram). Bianglala Informatika, $\operatorname{viii}(21)$. 